\title{
Recent developments in chemotherapy for meningiomas: a review
}

\author{
Alan A. Moazzam, M.D., ${ }^{1}$ Naveed Wagle, M.D., ${ }^{2}$ And Gabriel Zada, M.D. ${ }^{3}$ \\ Departments of ${ }^{1}$ General Internal Medicine, ${ }^{2}$ Neurology, and ${ }^{3}$ Neurosurgery, Keck School of Medicine, \\ University of Southern California, Los Angeles, California
}

\begin{abstract}
Object. Currently, few medical options exist for refractory and atypical/anaplastic meningiomas. New developments in chemotherapeutic options for meningiomas have been explored over the past decade. The authors review these recent developments, with an emphasis on emerging avenues for therapy, clinical efficacy, and adverse effects.

Methods. A review of the literature was performed to identify any studies exploring recent medical and chemotherapeutic agents that have been or are currently being tested for meningiomas. Results from included preclinical and human clinical trials were reviewed and summarized.

Results. Current guidelines recommend only 3 drugs that can be used to treat patients with refractory and highgrade meningiomas: hydroxyurea, interferon- $\alpha 2 \mathrm{~B}$, and Sandostatin long-acting release. Recent developments in the medical treatment of meningiomas have been made across a variety of pharmacological classes, including cytotoxic agents, hormonal agents, immunomodulators, and targeted agents toward a variety of growth factors and their signaling cascades. Promising avenues of therapy that are being evaluated for efficacy and safety include antagonists of platelet-derived growth factor receptor, epidermal growth factor receptor, vascular endothelial growth factor receptor, and mammalian target of rapamycin. Because malignant transformation in meningiomas is likely to be mediated by numerous processes interacting via a complex matrix of signals, combination therapies affecting multiple molecular targets are currently being explored and hold significant promise as adjuvant therapy options.

Conclusions. Improved understanding of the molecular mechanisms driving meningioma tumorigenesis and malignant transformation has resulted in the targeted development of more specific agents for chemotherapeutic intervention in patients with nonresectable, aggressive, and malignant meningiomas.
\end{abstract}

(http://thejns.org/doi/abs/10.3171/2013.10.FOCUS13341)

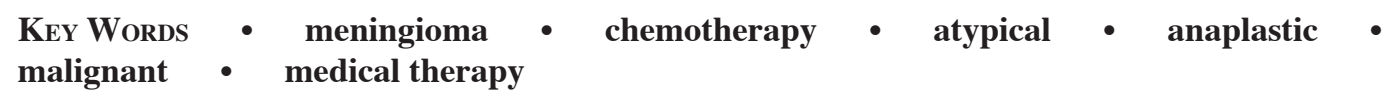

$\mathrm{M}$ ENINGIOMAS are the most common primary intracranial tumors. ${ }^{37}$ Although a majority of meningiomas are benign, slow-growing tumors that can be resected surgically, there remains a subset of patients with highly invasive, inoperable, recurrent, atypical, and malignant meningiomas that often require alternative or adjunctive therapies beyond resection. A common paradigm for the treatment of many invasive skull base meningiomas involves maximal safe tumor resection followed by radiosurgery or other radiation-based intervention for any residual disease. However, tumor progression following administration of radiation-based

\footnotetext{
Abbreviations used in this paper: EGF, EGFR = epidermal growth factor, EGF receptor; $\mathrm{GH}=$ growth hormone; IFN $\alpha=$ interferon- $\alpha$; IGF-I, -II = insulin-like growth factor-I, -II; MAPK = mitogen-activated protein kinase; $\mathrm{mTORC} 1, \mathrm{mTORC} 2=$ mammalian target of rapamycin complex 1 and 2; PDGF, PDGFR = plateletderived growth factor, $\mathrm{PDGF}$ receptor; $\mathrm{PIP}_{2}=$ phosphatidylinositol 4,5-bisphosphate; $\mathrm{PIP}_{3}=$ phosphatidylinositol 3,4,5-trisphosphate; PI3K = phosphoinositide 3-kinase; PLC- $\gamma 1-\mathrm{PKC}=$ phospholipase C-gamma1-protein kinase $\mathrm{C}$; TGF $\alpha$ and $-\beta=$ transforming growth factor $\alpha$ and $\beta$; VEGF $=$ vascular endothelial growth factor.
}

therapy remains a more daunting clinical challenge with few therapeutic options.

Although significant advances have been made in radiation therapy and stereotactic surgery over the past several decades, many patients will still be faced with the specter of aggressive meningiomas that are refractory to most conventional therapies, and their treatment options remain limited. The National Comprehensive Cancer Network (NCCN) published guidelines in 2011 suggesting only 3 drugs (hydroxyurea, interferon- $\alpha$ [IFN $\alpha$ ] $2 \mathrm{~B}$, and Sandostatin long-acting release) in the medical treatment of meningiomas. ${ }^{2}$ These recommendations, however, are based on a small number of studies, each with their own respective limitations. As advances are made in the understanding of the cell signaling pathways involved in the initiation and propagation of meningiomas, potential new targets for novel chemotherapeutic agents are rapidly being discovered and prioritized. Chemotherapeutics targeting these mechanisms can affect downstream signaling molecules that control various processes including cellular differentiation, cell proliferation, angiogenesis, and/or apoptosis. 
In this review we summarize the latest advances in the understanding of meningioma pathogenesis, and how these new insights can be translated into targeted and more effective chemotherapeutic agents. Classes of various agents discussed in this review include the following: 1) cytotoxic agents resulting in preferential cell death of highly active replicating cells; 2) hormonal agents, which cause modulation of hormonal influences on target tissues; 3) targeted molecular agents serving as antagonists or inhibiting specific receptors or cell signaling molecules to prevent aberrant cell signaling involved in malignant transformation; and 4) angiogenesis inhibitors, which act to limit tumor vascularization commonly seen in meningiomas.

\section{Methods}

The PubMed electronic database was searched for all English-language studies pertaining to medical management and chemotherapy for meningiomas within the last 2 decades. A broad search strategy was used, with any combination of the following key words: "meningioma," "chemotherapy," "cell signaling pathways," "medical management," and "neuro-oncology therapy." Additional studies were identified from references in relevant publications that had been found using the primary search strategy. In vitro investigations, animal studies, and human clinical trials were included in the review, and an emphasis was placed on mechanisms of action, clinical efficacy, and adverse effects. A total of 50 studies were included in the review and are summarized below according to general pharmacological classes (see also Fig. 1 and Table 1), including cytotoxic agents, hormonal agents, targeted-molecule agents, angiogenesis inhibitors, immunomodulator therapy, and combination therapies.

\section{Results}

\section{Cytotoxic Agents}

Cytotoxic agents preferentially kill cancer cells by taking advantage of their relatively rapid turnover. Numerous conventional cytotoxic agents, such as dacarbazine and adriamycin, have been studied over the years for treatment of meningiomas. Results from these trials have generally been disappointing. ${ }^{71}$ Newer agents such as temozolomide (Temodar, Schering-Plough), ${ }^{11}$ an alkylating agent, and irinotecan (Camptosar, Pfizer), ${ }^{10}$ a topoisomerase inhibitor, have also recently failed to show any significant efficacy. Additional cytotoxic agents, including hydroxyurea, trabectedin, and some plant-derived agents, have recently been tested for their role in the treatment of refractory meningiomas.

Hydroxyurea. Hydroxyurea is an oral ribonucleotide inhibitor that arrests the cell cycle in the $S$ phase and induces apoptosis. ${ }^{69,70}$ Initial enthusiasm for hydroxyurea arose from early trials showing some efficacy in smallscale studies. ${ }^{43,44,50,67}$ However, these trials recruited many patients in whom radiotherapy had not failed or in whom radiotherapy was administered concurrently, making the data interpretation somewhat problematic. Larger, more recent studies have also failed to demonstrate significant clinical efficacy. ${ }^{6,9}$ In a recent large-scale trial that included 60 patients, progression of disease occurred in $65 \%$ of participants despite hydroxyurea therapy. ${ }^{9} \mathrm{~A}$ follow-up retrospective study of 35 patients with WHO Grade II and Grade III meningiomas showed $57 \%$ progression of disease at 6 months. ${ }^{6}$ These results suggest that although hydroxyurea is generally well tolerated with limited toxicity, it appears to have very limited activity in tumor control. Investigators are currently looking at the role of hydroxyurea as an adjunct to other therapies, such as radiation or calcium channel blockers. Pilot studies with radiation have shown some promise. ${ }^{24}$

Trabectedin. This chemotherapeutic agent, which is already in use for treatment of soft-tissue sarcomas, is believed to work by binding to the minor groove of the DNA helix and inhibiting transcription factor binding. Trabectedin was investigated in a preclinical study published by Preusser et al., ${ }^{60}$ which revealed a statistically significant response to treatment of various meningioma cell lines. The group subsequently treated a single, heavily pretreated patient with this chemotherapeutic agent; this 64-year-old patient was reported to have initial relief of his neurological symptoms and aphasia, and MRI revealed reduction of perifocal edema; however, treatment had to be terminated after 5 cycles due to side effects of generalized edema and mucositis.

Plant-Derived Chemotherapeutic Agents. A handful of preclinical studies have been published in which medications extracted from various plants have been evaluated. Curic et al. ${ }^{12}$ described a dose-dependent response of meningioma cell lines exposed to curcumin, an active ingredient of the spice plant Curcuma longa, which is known to have antitumorigenic properties. Park et al. ${ }^{57}$ also demonstrated a potent cytotoxic effect of acetyl-11-keto-beta-boswellic acid, a naturally occurring substance isolated from the gum resin of Boswellia serrata (frankincense) trees, on 11 primary cell lines derived from human meningioma resections. This class of boswellic acid drugs are believed to work by inhibition of microsomal prostaglandin E synthase-1 and the serine protease cathepsin $\mathrm{G}$. $^{1}$

\section{Hormonal Agents}

Estrogen and Progesterone Receptor Antagonists. Various hormone therapies have been investigated for the treatment of meningiomas based on the finding that these tumors commonly express androgen-derivative receptors.

Progesterone antagonists were initially considered promising agents, given the fact that up to two-thirds of meningiomas express the progesterone receptor. Megestrol acetate (Megace) was one of the first drugs to be investigated, but did not show a significant clinical response in a small prospective clinical trial. ${ }^{20}$ Mifepristone (RU-486), a progesterone receptor antagonist, generated some excitement when early small-scale studies suggested a potential therapeutic benefit, but this was largely refuted by a multicenter randomized Phase III clinical trial in which 180 patients were enrolled, which failed to show any major 


\section{Review of chemotherapy options in meningioma}

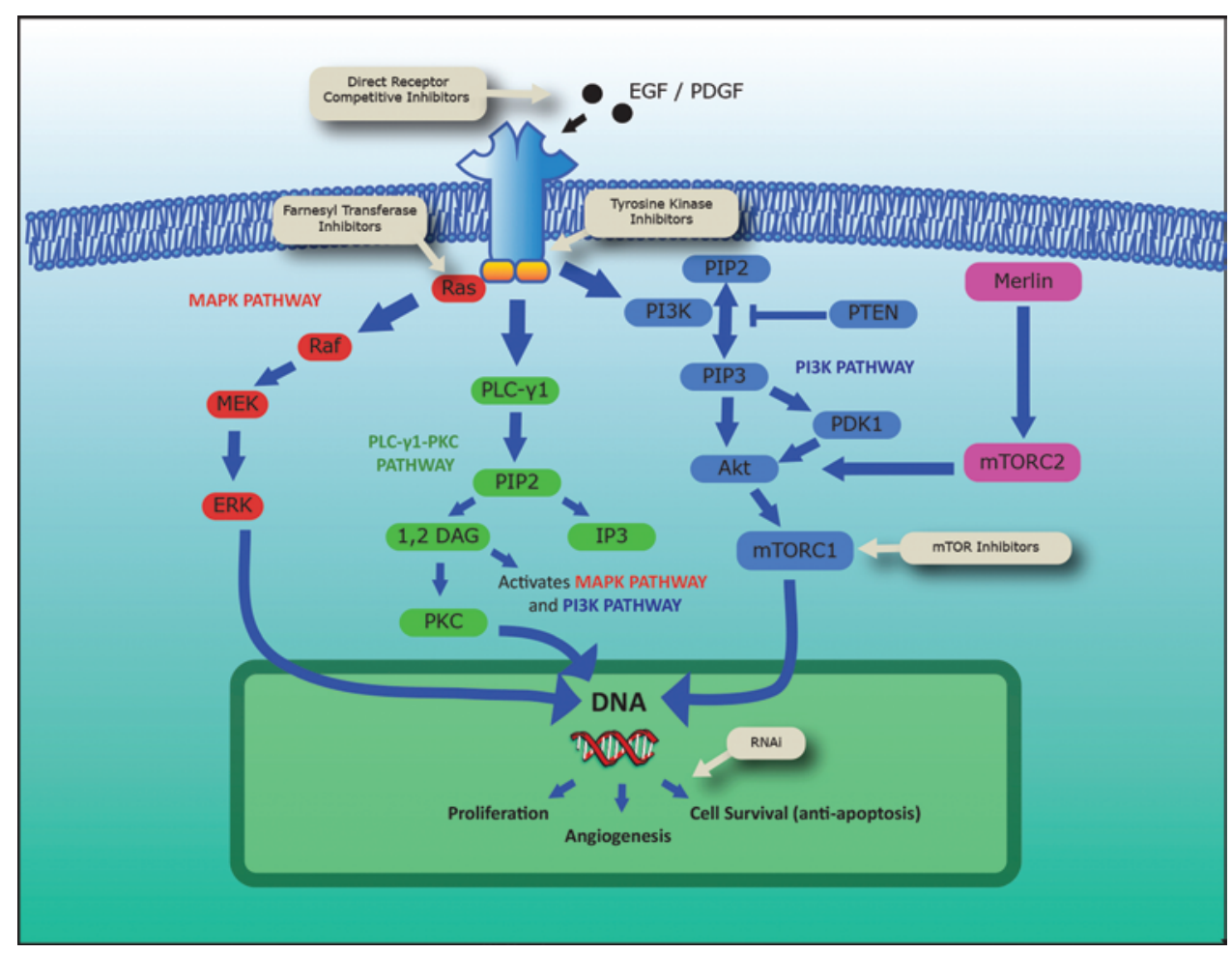

FIG. 1. Simplified scheme of cell signaling pathways involved in meningioma pathogenesis. IP3 = inositol 1,4,5-trisphosphate; PDK1 = phosphoinositide-dependent kinase-1; PTEN = phosphatase and tensin homolog; RNAi = RNA interference; 1,2-DAG $=1,2$-diacylglycerol.

clinical benefit. ${ }^{19,21}$ A major limitation of this study, aside from a small sample size and heterogeneous pretrial treatment histories (that is, prior surgery, radiosurgery, and so on), was that progesterone receptor expression is often not retained in the setting of tumor progression and malignant transformation of meningiomas, and most patients recruited in this trial had more aggressive meningioma subtypes. ${ }^{79}$

Tamoxifen, an estrogen receptor antagonist, was also investigated as a possible candidate drug. A Phase II study including 19 patients, however, only showed a partial or minor response in 3 of the study participants. ${ }^{17}$ Given that only $10 \%$ of meningiomas express estrogen receptors, this finding was somewhat unsurprising.

Growth Hormone and Insulin-Like Growth Factor-I and $-I I$. The observation that growth hormone $(\mathrm{GH})$ receptors are ubiquitously expressed in meningioma cells, and that inhibition of GH receptors in vitro results in decreased meningioma cell proliferation,$^{14}$ has generated some interest in this line of therapy. Growth hormone is secreted into the bloodstream by the pituitary gland, and subsequently induces the production of insulin-like growth factor-I (IGF-I) from the liver. Together, these hormones influence many aspects of normal growth and metabolism. Pegvisomant, a pegylated GH analog, is a competitive inhibitor of the GH receptor. McCutcheon et al. ${ }^{46}$ used this analog in an in vivo animal study in which human meningioma xenografts were implanted into mice. The investigators observed significantly reduced growth in specimens treated with pegvisomant. They concluded that the effects of pegvisomant were mediated via 2 processes: 1) direct blockade of the GH receptor, and 2) indirect downregulation of IGF-I serum concentrations. Similarly, Puduvalli et al. ${ }^{62}$ recently demonstrated increased induction of apoptosis in meningioma cell cultures exposed to fenretinide, a synthetic retinoid that, among other effects, is known to inhibit IGF-I-induced proliferation.

Insulin-like growth factor-II is another growth-promoting hormone that similarly acts on the IGF-I receptor. Several studies based on human cell cultures have demonstrated that the invasiveness of meningiomas is correlated to levels of IGF-II expression. ${ }^{53,54,77}$ It remains unclear, however, whether manipulation of these IGF pathways can inhibit or reverse meningioma progression.

Somatostatin. Somatostatins are a family of cyclopeptides that act on a wide range of physiological processes, including inhibition of endocrine factor release and inhibition of cell proliferation. Meningiomas are known to have a high frequency of somatostatin receptors, ${ }^{8}$ in particular the sst2A subtype. In the largest trial of somatostatin use in meningiomas, 16 patients were treated with a long-acting somatostatin (Sandostatin LAR), and a partial response was achieved in one-third of patients. ${ }^{8}$ Another one-third of patients in this trial had stable disease, and the final one-third showed clinical progression. The authors suggested that octreotide scintigraphy can be used as an imaging modality to identify patients with meningiomas that express somatostatin receptors, conferring a higher likelihood of responding to somatostatin treatment. Pasireotide, a long-acting somatostatin analog administered via an intramuscular route, has a wider somatostatin receptor spectrum and is currently undergoing 
TABLE 1: List of potential medications for treatment of meningiomas*

\begin{tabular}{|c|c|c|}
\hline Medication & Mechanism of Action & Stage of Investigation $\dagger$ \\
\hline \multicolumn{3}{|l|}{ cytotoxic agents } \\
\hline temozolomide (Temodar) & alkylating agent & Phase II trial: no clinical efficacy shown \\
\hline irinotecan (Camptosar) & topoisomerase 1 inhibitor & Phase II trial: no clinical efficacy shown \\
\hline hydroxyurea & ribonucleotide reductase inhibitor & Phase II trial: mixed results \\
\hline trabectedin (Yondelis) & $\begin{array}{l}\text { mechanism unclear; believed to make conformational changes to } \\
\text { DNA strand, causing inhibition of transcription factor binding }\end{array}$ & preclinical: cell culture/in vitro \\
\hline \multicolumn{3}{|l|}{ plant-derived agents } \\
\hline curcumin & interaction w/ multiple cell signaling proteins & preclinical: cell culture/in vitro \\
\hline AKBA & induction of apoptosis, antiinflammatory & preclinical: cell culture/in vitro \\
\hline \multicolumn{3}{|l|}{ hormonal agents } \\
\hline \multicolumn{3}{|c|}{ progesterone receptor binding agents } \\
\hline megestrol (Megace) & progesterone receptor partial agonist & SSCT: no survival benefit shown \\
\hline mifepristone (RU-486) & progesterone receptor competitive antagonist & Phase III: no survival benefit shown \\
\hline \multicolumn{3}{|l|}{ estrogen antagonists } \\
\hline tamoxifen & estrogen receptor competitive antagonist & SSCT: no survival benefit shown \\
\hline \multicolumn{3}{|l|}{ somatostatins } \\
\hline octreotide (Sandostatin) & somatostatin mimetic & Phase II: some stabilization of disease \\
\hline pasireotide (Signifor) & somatostatin mimetic, long-acting & Phase II trial: ongoing \\
\hline \multicolumn{3}{|l|}{ GH receptor antagonists } \\
\hline pegvisomant (Somavert) & pegylated GH receptor antagonist & preclinical: animal models \\
\hline \multicolumn{3}{|l|}{ IGF-I \& -II antagonists } \\
\hline fenretinide & synthetic retinoid derivative & preclinical: cell culture/in vitro \\
\hline \multicolumn{3}{|l|}{ PDGFR antagonists } \\
\hline imatinib (Gleevec) & PDGFR antagonist & Phase II: some stabilization of disease \\
\hline nilotinib/dasatinib & 2nd-generation PDGFR inhibitors & no studies \\
\hline \multicolumn{3}{|l|}{ EGFR antagonists } \\
\hline gefitinib (Iressa) & EGFR antagonist & Phase II: no survival benefit shown \\
\hline erlotinib (Tarceva) & EGFR antagonist & Phase II: no survival benefit shown \\
\hline monoclonal antibodies & humanized monoclonal antibodies to EGFR & no studies \\
\hline \multicolumn{3}{|l|}{ VEGFR antagonists } \\
\hline bevacizumab (Avastin) & humanized monoclonal antibody to VEGFR & SSCTs: mixed results \\
\hline cediranib (Recentin) & VEGFR antagonist & no studies \\
\hline \multicolumn{3}{|l|}{ combination antagonists } \\
\hline sorafenib (Nexavar) & dual VEGFR \& PDGFR antagonist & no studies \\
\hline sunitinib (Sutent) & dual VEGFR \& PDGFR antagonist & Phase II: some stabilization of disease \\
\hline vatalanib (PTK787) & dual VEGFR \& PDGFR antagonist & Phase II: some stabilization of disease \\
\hline \multicolumn{3}{|l|}{ farnesyl transferase inhibitors } \\
\hline tipifarnib (Zarnestra) & farnesyl transferase inhibitor & no studies \\
\hline \multicolumn{3}{|l|}{ mTOR inhibitors } \\
\hline temsirolimus (Torisel) & mTOR inhibitor & no studies \\
\hline everolimus (Afinitor) & mTOR inhibitor & no studies \\
\hline \multicolumn{3}{|l|}{ immunomodulators } \\
\hline IFN $\alpha$ 2B & antiproliferative \& antiangiogenic properties & Phase II: mixed results \\
\hline PD-1/PD-L1 inhibitors & PD-1 receptor \& ligand inhibitors & no studies \\
\hline TL4 inhibitors & $\begin{array}{l}\text { binding to TL4, preventing escape of immune surveillance mecha- } \\
\text { nisms }\end{array}$ & preclinical: cell cultures/in vitro \\
\hline \multicolumn{3}{|l|}{ possible adjunctive agents } \\
\hline calcium channel blockers & reduction of intracellular calcium concentrations & preclinical: animal models \\
\hline statins & inhibition of MAPK pathway & preclinical: cell culture/in vitro \\
\hline
\end{tabular}

(continued) 
Review of chemotherapy options in meningioma

TABLE 1: List of potential medications for treatment of meningiomas* (continued)

\begin{tabular}{lll}
\hline \multicolumn{1}{c}{ Medication } & Mechanism of Action & Stage of Investigation† \\
\hline $\begin{array}{l}\text { possible adjunctive agents (continued) } \\
\text { antiretrovirals }\end{array}$ & survivin protein downregulation & preclinical: cell culture/in vitro \\
RNAi & antisense abrogation of mRNA strands & preclinical: cell culture/in vitro \\
\hline
\end{tabular}

* AKBA = acetyl-11-keto-beta-boswellic acid; PD-1/PD-L1 = programmed death-1/programmed death-1 ligand; RNAi = RNA interference; SSCT = small-scale clinical trial; TL4 = Toll-like receptor 4; VEGFR = VEGF receptor.

$\dagger$ Most advanced published stage of investigation with meningiomas.

a Phase II trial. Midstudy results released in abstract form showed that of the 26 patients who have been treated with pasireotide, 16 achieved stable disease. ${ }^{51}$ No radiographic responses were observed so far, however.

\section{Targeted Molecule Chemotherapeutic Agents}

Cytogenetics and Tumor Suppressor Proteins. Understanding the underlying genetics of meningioma tumorigenesis and transformation remains a top priority for investigators, because it is generally hoped that specific and novel targets for therapeutic intervention will be discovered. To this end, a family of membrane-bound proteins known as the Band 4.1 family has been discovered on the cytoplasmic side of the cell membrane, and may play a key role in meningioma development. ${ }^{23,58}$ These proteins link membrane-bound structures to the cellular cytoskeleton and are thought to be involved with cell structure, but also may regulate cell proliferation. Genetic mutations that lead to abnormal function of these proteins are believed to be one of the main causes for meningioma development.

Merlin. Inactivation of the tumor suppressor gene Neurofibromatosis $2(N F-2)$ via loss of heterozygosity of chromosome $22 \mathrm{q} 12.2$, is found in $60 \%$ of all meningiomas. ${ }^{13}$ Inactivation of this gene leads to a deficiency of merlin (sometimes alternatively referred to as "schwannomin"), which is a member of the ERM (ezrin-radixinmoesin) family of proteins ${ }^{72}$ and the Band 4.1 superfamily of proteins. ${ }^{65}$ The functions of merlin are not well understood, but it is believed that they involve regulation of cell proliferation pathways. ${ }^{72}$ Expression of $N F-2$ and merlin inactivation varies among WHO Grade I meningioma subtypes. ${ }^{41,65}$ For instance, $70 \%-80 \%$ of fibroblastic and transitional meningiomas possess the mutation, whereas only $25 \%$ of meningoepithelial and $1 \%$ of secretory meningiomas have the mutation, possibly suggesting alternative tumorigenesis pathways among these subtypes. ${ }^{4}$ Similarly, only $40 \%$ of sporadic meningiomas possess the $N F-2$ mutation. ${ }^{65}$ On the other hand, within subtypes in which the mutation does occur, there appears to be no major variation in frequency among the different tumor grades, ${ }^{3}$ suggesting that this alteration is more likely to be involved with meningioma initiation rather than malignant transformation. ${ }^{78}$

Although this observation initially invited skepticism that manipulation of the merlin function would have any practical benefits for patients with already established meningiomas, more recent literature now suggests that merlin may continue to play a prominent role in meningioma propagation. The intracellular functions of the merlin protein are slowly being elucidated. Although Stamenkovic and $\mathrm{Yu}^{72}$ published a review detailing the myriad downstream and intracellular effects of merlin, few have been investigated specifically in meningioma cells to date. Lee et al. ${ }^{40}$ linked merlin function to inhibition of transactivation-responsive RNA-binding protein, a double-stranded RNA-binding protein involved in tumorigenesis and cell proliferation in $N F-2$ mouse models. More significantly, James et al. ${ }^{27}$ recently published their observation that merlin may play a role in regulation of the mammalian target of rapamycin complex 2 (mTORC2), a protein complex that modulates the effect of the Akt protein within the phosphoinositide 3-kinase [PI3K]-Akt-mTORC1 pathway, which is explained in more detail below.

Protein 4.1B. Another 4.1 family protein believed to have tumor suppression properties is protein $4.1 \mathrm{~B}$, which is encoded by the $D A L-1$ gene. Gutmann et al. have shown that loss of protein 4.1B appears to be equally distributed among the meningioma grades, again suggesting an early event in the formation of meningiomas. ${ }^{23,58}$ It has been observed, however, that transgenic mice lacking $D A L$ 1 do not develop tumors, suggesting that the mutation is primarily involved with progression of disease rather than initiation. ${ }^{23}$ Downstream effects of protein $4.1 \mathrm{~B}$ include activation of a JNK (c-Jun-NH2-kinase) protein, which results in reduced cell growth via decreased cyclin A expression and phosphorylation of the retinoblastoma protein. ${ }^{16}$ Protein $4.1 \mathrm{~B}$ has been shown to interact with the cell growth regulator protein 14-3-3. Although aggressive meningiomas show reduced levels of 14-3-3 expression, impaired 14-3-3 function has not been shown to affect protein $4.1 \mathrm{~B}$ function, suggesting that alternative signaling pathways are present. ${ }^{45}$

Growth Factor Receptor and Downstream Signaling Pathway Inhibitors. A wide variety of growth factors and cytokines have been implicated in the formation and propagation of meningiomas. These include platelet-derived growth factor (PDGF), epidermal growth factor (EGF), transforming growth factors $\alpha$ and $\beta$ (TGF $\alpha$ and TGF $\beta$ ), stromal cell-derived growth factor $\beta$, and bone morphogenetic proteins. ${ }^{65}$ Models describing the aberrant cell signaling cascades that occur with meningioma initiation and growth are gradually emerging. It is becoming increasingly apparent that PDGF and EGF play vital roles in the activation of these cascades. Both of these growth factors have been associated with activation of 2 main antiapoptotic cell signaling pathways (Ras/mitogen-activated protein kinase 
[MAPK] and PI3K-Akt) and 1 secondary pathway (phospholipase C-gamma1-protein kinase C [PLC- $\gamma 1-\mathrm{PKC}])^{30}$ Conceptually, targets for therapeutic agents can be broken down into the following categories: inhibitors of growth factor receptors and inhibitors of downstream signaling molecules involved in the activation cascades.

The Ras/MAPK Pathway. The binding of PDGF and/ or EGF to their respective receptors induces receptor dimerization and subsequent activation of tyrosine kinases. ${ }^{30}$ This causes autophosphorylation of tyrosine residues on the cytoplasmic side of the receptor. These residues can then bind to the proteins Grb2 and Sos, bringing them in close proximity with the cell membrane. This causes activation of Ras, which in turn activates downstream Raf, MEK-1, and ERK, eventually leading to phosphorylation and activation of various transcription factors within the nucleus. Inhibition of this pathway with selective MEK-1 inhibitors has shown diminished MAPK activity and associated inhibition in meningioma cell cultures. ${ }^{32}$ Farnesyl transferase inhibitors, a class of chemotherapeutic agents that work by blocking farnesyl transferase and thereby inhibiting Ras localization and activation to the cytoplasmic surface of the receptor, are currently under investigation for a variety of hematological and solid tumors. These may hold promise for meningioma treatment as well, although several monotherapy trials using tipifarnib (Zarnestra) in gliomas have been disappointing to date. ${ }^{47}$

RNA interference technology has also been used in an attempt to modulate this pathway. Tummalapalli et al. $^{76}$ used a plasmid vector to transfect meningioma cells in vitro and in vivo with complementary doublestranded RNA to cathepsin B and matrix metalloproteinase-9 mRNA. This resulted in decreased expression of these enzymes and significantly reduced activity of both MAPK and PI3K pathways, in addition to reducing meningioma migration and invasiveness. This anticancer technique holds much promise in the future therapy of meningioma treatment, especially if and when effective molecular targets are identified.

Statin drugs, currently in widespread use for cholesterol control, have also been studied as potential agents for meningioma treatment. These drugs have pleiotropic properties, one of which is inhibition of the MAPK pathway. Results thus far are derived from in vitro studies only, and show favorable results..$^{15,33}$

Tichomirowa et al. ${ }^{73}$ recently published an in vitro study in which an entirely novel strategy of inducing apoptosis in meningioma cells via inhibition of Toll-like receptor 4 with paclitaxel was used. The meningioma cell cultures used in this experiment exhibited dose- and time-dependent growth suppression following paclitaxel treatment, which was further amplified following addition of a statin medication.

The PI3K-Akt-mTORC1 Pathway. The PI3K pathway is the second, parallel pathway by which meningioma induction and propagation via growth factor influences are mediated. The PDGF and/or EGF bind to their respective receptors, resulting in allosteric activation of a catalytic unit on the cytoplasmic side of the receptor, inducing autophosphorylation. ${ }^{30}$ This initiates an activation cascade of nearby adaptor proteins that results in activation of PI3K protein via its $\mathrm{p} 110$ subunit. The PI3K goes on to catalyze the conversion of phosphatidylinositol 4,5-bisphosphate $\left(\mathrm{PIP}_{2}\right)$ to PIP 3,4,5-trisphosphate $\left(\mathrm{PIP}_{3}\right)$, a reaction that is controlled and inhibited by PTEN (phosphatase and tensin homolog on chromosome 10). ${ }^{30,83}$ With aid of the mTORC2, PIP $_{3}$ activates Akt protein. In turn, Akt initiates several downstream processes, one of which is activation of mTOR, an atypical serine/threonine $(\mathrm{S} / \mathrm{T})$ protein kinase, which subsequently acts as a catalyst for formation of the mTORC1. ${ }^{83}$ The mTORC1 acts as a "master switch" for regulation of cell growth and proliferation.

The mTOR Inhibitors. The mTOR inhibitors are presently being investigated in numerous tumor types, including intracranial malignancies such as glioblastoma multiforme. A few preclinical trials have been published with regard to meningioma specifically. Pachow et al. ${ }^{56}$ recently published a study demonstrating significant reductions in meningioma cell growth in mouse models treated with the mTOR inhibitor drugs temsirolimus and everolimus.

The PLC- $\gamma 1-$ PKC Pathway. This third pathway appears to be associated with cross-activation of both the MAPK and PI3K pathways, and therefore presents a third potential target for intervention. Mediators of this pathway go on to activate the MAPK and PI3K pathways simultaneously..$^{30}$ The presence of this third pathway suggests that significant cross-talk occurs between each signaling cascade, and combinations of multiple inhibitors will probably be needed to achieve significant effects.

The PDGF Inhibitors. The PDGF receptors (PDGFRs) are abundantly expressed on meningioma cells, and it is believed that PDGF stimulates meningioma proliferation via autocrine and paracrine mechanisms. ${ }^{71}$ Receptor expression levels have also been associated with histological tumor grade. ${ }^{81}$ The PDGF promotes meningioma growth mainly via aberrant signaling of one of the two kinase cascades presented above. Imatinib mesylate, a chemotherapeutic agent already in use for the treatment of leukemias and gastrointestinal stromal tumors, is a potent inhibitor of the PDGFR and has been proposed as a possible therapeutic agent. Two Phase II trials have been conducted looking at the use of imatinib alone $e^{80}$ and in conjunction with hydroxyurea ${ }^{66}{ }^{6}$ enrolling 23 and 21 patients, respectively. Both trials had single arms.

In the monotherapy study conducted by the North American Brain Tumor Consortium (NABTC), response to therapy was evaluated in 19 patients. ${ }^{80}$ Of these 19 patients, 10 had progression of disease and 9 had stable disease. No patient demonstrated disease regression. In the subsequent Phase II trial involving both imatinib and hydroxyurea, no patient achieved either complete or partial response, and 14 patients achieved disease stability. ${ }^{66}$ Horak et al. ${ }^{26}$ recently published a retrospective study looking at the role of imatinib treatment on progressionfree survival in patients with meningioma. Of the $18 \mathrm{pa}-$ tients in their study, 9 received imatinib based on PDGFR positivity; of those 9, 7 had stable disease and 2 showed disease progression at the time of their first 3-month follow-up imaging. Although no complete or partial responses were observed, a $66.7 \%$ progression-free survival 
rate was achieved at 6 months in their treatment cohort, along with a median progression-free survival time of 16 months. No survival data were reported for the non-imatinib treated cohort.

Taking the results of the above studies into account, it appears that imatinib may play a role in disease stabilization in selected meningioma subtypes; however, no demonstrable data exist that show disease regression in patients treated with imatinib. Gupta et al. ${ }^{22}$ published a preclinical study showing that the addition of nelfinavir, an antiretroviral drug, to imatinib therapy can potentiate its efficacy. Similarly, Johnson et al. ${ }^{31}$ published their preclinical experiment, which showed reduced meningioma growth in cell lines exposed to lopinavir, another antiretroviral drug. Second-generation PDGF inhibitors such as nilotinib or dasatinib that have since been developed and are thought to be more potent inhibitors have not been tested on meningioma cells.

The EGF Inhibitors. The EGF receptors (EGFRs) are overexpressed in up to $60 \%$ of meningiomas, ${ }^{5,34}$ and can be activated by both EGF and tumor necrosis factor- $\alpha$, both of which are present in CSF. As with PDGF, these receptors are also believed to activate the MAPK and PI3K pathways. This activation has been shown to stimulate meningioma cell proliferation in vitro. ${ }^{30}$ Gefitinib and erlotinib, two EGFR inhibitors, were recently investigated based on these findings. ${ }^{52}$ Twenty-five patients with recurrent meningiomas were treated with either gefitinib (64\%) or erlotinib (36\%); 12-month follow-up data did not appear to show a significant survival benefit. Humanized monoclonal antibodies to the EGFR, including cetuximab, panitumumab, matuzumab, and nimotuzumab, are being investigated, and may prove to be more efficacious than first-generation EGFR inhibitors.

Activation of the SMAD Pathway by TGF $\beta$. Investigators have demonstrated that in vitro inhibition of cell growth and proliferation can be achieved by activation of the SMAD pathway using TGFb. ${ }^{30} \mathrm{~A}$ variety of TGF subtypes are constitutively present in CSF, and probably play a chronic inhibitory role in the development of meningiomas. This theory has also been borne out in studies involving low-grade astrocytomas and benign intestinal adenomas. ${ }^{30}$ In both of these instances, however, with progressive dedifferentiation of malignant cells, this inhibitory affect eventually "switches" to instead promote rapid cell proliferation. Elucidating the causes of this switch may present yet another target for meningioma therapy.

Calcium Channel Blockers. As described above, cellsignaling pathways of many tumorigenic factors are mediated by protein cascades that are highly dependent on high levels of cytoplasmic calcium concentrations for activity. This finding has led to some interest in assessing the efficacy of calcium channel blockers for the inhibition of meningioma growth. Various mechanisms have been proposed for how these drugs specifically affect cell signaling. A leading theory hypothesizes that modulation or inhibition of inositol phosphate-3, an intracellular messenger necessary for calcium release from internal stores, causes decreased proliferative activity. ${ }^{28,74}$ Therefore, investigators have looked into the benefit of adding calcium channel blockers, such as verapamil or diltiazem, to treatment with hydroxyurea or mifepristone. ${ }^{29,64}$ These in vitro and xenografted in vivo studies showed a dose-dependent decrease in malignant cell population and tumor size with the addition of calcium channel blockers. Human clinical trials were subsequently proposed. ${ }^{63}$

\section{Angiogenesis Inhibition}

Vascular Endothelial Growth Factor. Because meningiomas are often particularly vascular tumors, the use of preoperative endovascular embolization has become common for a subset of meningiomas, or when significant intraoperative bleeding is anticipated. Vascular endothelial growth factor (VEGF) has been implicated as a major mediator of aberrant angiogenesis in these tumors. ${ }^{39}$ Levels of VEGF expression have been associated with meningioma grade and also with the degree of peritumoral brain edema. ${ }^{48,61}$ Bevacizumab (Avastin), a humanized monoclonal antibody direct VEGF inhibitor, has been investigated as a possible therapeutic agent that could halt or reverse tumor-related angiogenesis. Several small-scale retrospective studies have been published, with mixed results, ${ }^{42,49,55}$ and there is a need for larger Phase II trials. The VEGF has also been shown to crossactivate other growth factor pathways, ${ }^{59}$ an observation that seems to be a recurring theme with new advances in understanding of cell signaling in meningiomas.

Other Antiangiogenic Agents. Additional candidates for antiangiogenic therapy include TNP-470, a synthetic analog of fumagillin, ${ }^{82}$ Endothelin-A receptor antagonists, ${ }^{25}$ and verotoxin, an antineoplastic agent that targets glycolipids on tumor cells. ${ }^{68}$

\section{Immunomodulator Therapy}

Interferon- $\alpha 2 B$. Interferon- $\alpha$ is a leukocyte-produced cytokine that has been shown to have antiproliferative, immunomodulatory, and antiangiogenic properties in meningiomas. ${ }^{35,38}$ The most extensive Phase II study to date was published by Chamberlain and Glantz. ${ }^{7}$ They enrolled 35 patients for treatment with IFN $\alpha$ therapy. Although the patients did not demonstrate significant toxicity, none of them experienced complete or partial responses; 26 patients (74\%) had stable disease for at least 12 weeks, and the median overall survival was 8 months. Given the lack of control data, it remains unclear how efficacious IFN $\alpha$ may be in treating patients with refractory meningioma. Furthermore, with a median survival of only 8 months, it is possible that this was a group selected for patients with a particularly poor prognosis.

Programmed Cell Death. Some of the latest advances in oncology are within the immunomodulator class. Programmed death-1 (PD-1) and its ligands (PD-L1 and PD-L2) have been shown to be upregulated by various types of cancer cells. ${ }^{75}$ This receptor-ligand system acts by downregulating the immune system's innate antitumor control mechanisms. Preliminary translational studies are currently underway for various cancer types. Meningioma research, however, remains lacking in this field. 


\section{Combination Therapy}

Due to the extent of cross-activation and interdependence of the signaling pathways discussed above, it is more likely that effective chemotherapy will require simultaneous inhibition of several mediators at once. This may account for the disappointing outcomes of some of the monotherapy trials described above, despite promising preclinical results. Some investigators have looked into inhibition of multiple targets of aberrant signaling. For example, vatalanib (PTK787) was developed as a dual inhibitor of VEGF and PDGF. In a Phase II trial, 21 patients with Grade II and III meningiomas were treated with vatalanib. ${ }^{18}$ Only 1 patient showed a partial response, 12 remained stable, and 5 had tumor progression. Similarly, sunitinib (Sutent), a tyrosine kinase inhibitor that targets both VEGF and PDGF, was tested in a Phase II trial, resulting in 6-month progression-free survival in $36 \%$ of participants and a median progression-free survival of 5.1 months. ${ }^{36}$

\section{Conclusions}

Our understanding of meningioma cell biology has progressed significantly in recent years, and has facilitated the development of various targeted therapies that hold promise for adjuvant intervention in patients with refractory and high-grade meningiomas. Further clinical investigations are needed to determine the efficacy and adverse event profiles of many of these novel agents. Of particular interest are combination therapies that affect multiple pathways, because it appears that the transformation to malignancy is mediated by numerous processes interacting via a complex matrix of signals. Deciphering this complexity will help confer more precise therapies in patients with various subsets of meningiomas requiring medical intervention.

\section{Disclosure}

The authors report no conflict of interest concerning the materials or methods used in this study or the findings specified in this paper.

Author contributions to the study and manuscript preparation include the following. Conception and design: Zada, Moazzam. Analysis and interpretation of data: Moazzam. Drafting the article: Moazzam. Critically revising the article: all authors. Reviewed submitted version of manuscript: all authors.

\section{References}

1. Abdel-Tawab M, Werz O, Schubert-Zsilavecz M: Boswellia serrata: an overall assessment of in vitro, preclinical, pharmacokinetic and clinical data. Clin Pharmacokinet 50:349369, 2011

2. Brem SS, Bierman PJ, Brem H, Butowski N, Chamberlain MC, Chiocca EA, et al: Central nervous system cancers. J Natl Compr Canc Netw 9:352-400, 2011

3. Buccoliero AM, Castiglione F, Rossi Degl'Innocenti D, Sardi I, Genitori L, Taddei GL: Merlin expression in pediatric anaplastic ependymomas real time PCR study. Fetal Pediatr Pathol 29:245-254, 2010

4. Buccoliero AM, Gheri CF, Castiglione F, Ammannati F, Gallina P, Taddei A, et al: Merlin expression in secretory me- ningiomas: evidence of an NF2-independent pathogenesis? Immunohistochemical study. Appl Immunohistochem Mol Morphol 15:353-357, 2007

5. Carroll RS, Black PM, Zhang J, Kirsch M, Percec I, Lau N, et al: Expression and activation of epidermal growth factor receptors in meningiomas. J Neurosurg 87:315-323, 1997

6. Chamberlain MC: Hydroxyurea for recurrent surgery and radiation refractory high-grade meningioma. J Neurooncol 107:315-321, 2012

7. Chamberlain MC, Glantz MJ: Interferon-alpha for recurrent World Health Organization grade 1 intracranial meningiomas. Cancer 113:2146-2151, 2008

8. Chamberlain MC, Glantz MJ, Fadul CE: Recurrent meningioma: salvage therapy with long-acting somatostatin analogue. Neurology 69:969-973, 2007

9. Chamberlain MC, Johnston SK: Hydroxyurea for recurrent surgery and radiation refractory meningioma: a retrospective case series. J Neurooncol 104:765-771, 2011

10. Chamberlain MC, Tsao-Wei DD, Groshen S: Salvage chemotherapy with CPT-11 for recurrent meningioma. J Neurooncol 78:271-276, 2006

11. Chamberlain MC, Tsao-Wei DD, Groshen S: Temozolomide for treatment-resistant recurrent meningioma. Neurology 62: 1210-1212, 2004

12. Curic S, Wu Y, Shan B, Schaaf C, Utpadel D, Lange M, et al: Curcumin acts anti-proliferative and pro-apoptotic in human meningiomas. J Neurooncol 113:385-396, 2013

13. Fathi AR, Roelcke U: Meningioma. Curr Neurol Neurosci Rep 13:337, 2013

14. Friend KE, Radinsky R, McCutcheon IE: Growth hormone receptor expression and function in meningiomas: effect of a specific receptor antagonist. J Neurosurg 91:93-99, 1999

15. Gehring S, Tapia-Pérez JH, Kirches E, Firsching R, Keilhoff G, Schneider T, et al: Cytotoxic effects of statins and thiazolidinediones on meningioma cells. J Neurooncol 102:383-393, 2011

16. Gerber MA, Bahr SM, Gutmann DH: Protein 4.1B/differentially expressed in adenocarcinoma of the lung-1 functions as a growth suppressor in meningioma cells by activating Rac1dependent c-Jun-NH(2)-kinase signaling. Cancer Res 66: 5295-5303, 2006

17. Goodwin JW, Crowley J, Eyre HJ, Stafford B, Jaeckle KA, Townsend JJ: A phase II evaluation of tamoxifen in unresectable or refractory meningiomas: a Southwest Oncology Group study. J Neurooncol 15:75-77, 1993

18. Grimm SA, Chamberlain MC, Chandler J, Muro K, Rice L, McCathy K, et al: A phase II trial of PTK787/ZK 222584 (PTK787) in recurrent high-grade meningioma. J Clin Oncol 29 (15 Suppl):2046, 2011 (Abstract)

19. Grunberg SM, Rankin C, Townsend J, Ahmadi J, Feun L, Fredericks R, et al: Phase III double-blind randomized placebo-controlled study of mifepristone (RU) for the treatment of unresectable meningioma. Proc Am Soc Clin Oncol 20:56a, 2001 (Abstract)

20. Grunberg SM, Weiss MH: Lack of efficacy of megestrol acetate in the treatment of unresectable meningioma. J Neurooncol 8:61-65, 1990

21. Grunberg SM, Weiss MH, Russell CA, Spitz IM, Ahmadi J, Sadun A, et al: Long-term administration of mifepristone (RU486): clinical tolerance during extended treatment of meningioma. Cancer Invest 24:727-733, 2006

22. Gupta V, Samuleson CG, Su S, Chen TC: Nelfinavir potentiation of imatinib cytotoxicity in meningioma cells via survivin inhibition. Neurosurg Focus 23(4):E9, 2007

23. Gutmann DH, Donahoe J, Perry A, Lemke N, Gorse K, Kittiniyom K, et al: Loss of DAL-1, a protein 4.1-related tumor suppressor, is an important early event in the pathogenesis of meningiomas. Hum Mol Genet 9:1495-1500, 2000

24. Hahn BM, Schrell UM, Sauer R, Fahlbusch R, Ganslandt O, 
Grabenbauer GG: Prolonged oral hydroxyurea and concurrent 3d-conformal radiation in patients with progressive or recurrent meningioma: results of a pilot study. $\mathbf{J}$ Neurooncol 74:157-165, 2005

25. Harland SP, Kuc RE, Pickard JD, Davenport AP: Expression of endothelin(A) receptors in human gliomas and meningiomas, with high affinity for the selective antagonist PD156707. Neurosurgery 43:890-899, 1998

26. Horak P, Wöhrer A, Hassler M, Hainfellner J, Preusser M, Marosi C: Imatinib mesylate treatment of recurrent meningiomas in preselected patients: a retrospective analysis. J Neurooncol 109:323-330, 2012

27. James MF, Stivison E, Beauchamp R, Han S, Li H, Wallace MR, et al: Regulation of mTOR complex 2 signaling in neurofibromatosis 2-deficient target cell types. Mol Cancer Res 10:649-659, 2012

28. Jensen RL, Petr M, Wurster RD: Calcium channel antagonist effect on in vitro meningioma signal transduction pathways after growth factor stimulation. Neurosurgery 46:692-703, 2000

29. Jensen RL, Wurster RD: Calcium channel antagonists inhibit growth of subcutaneous xenograft meningiomas in nude mice. Surg Neurol 55:275-283, 2001

30. Johnson M, Toms S: Mitogenic signal transduction pathways in meningiomas: novel targets for meningioma chemotherapy? J Neuropathol Exp Neurol 64:1029-1036, 2005

31. Johnson MD, O'Connell M, Pilcher W: Lopinavir inhibits meningioma cell proliferation by Akt independent mechanism. J Neurooncol 101:441-448, 2011

32. Johnson MD, Woodard A, Kim P, Frexes-Steed M: Evidence for mitogen-associated protein kinase activation and transduction of mitogenic signals by platelet-derived growth factor in human meningioma cells. J Neurosurg 94:293-300, 2001

33. Johnson MD, Woodard A, Okediji EJ, Toms SA, Allen GS: Lovastatin is a potent inhibitor of meningioma cell proliferation: evidence for inhibition of a mitogen associated protein kinase. J Neurooncol 56:133-142, 2002

34. Jones NR, Rossi ML, Gregoriou M, Hughes JT: Epidermal growth factor receptor expression in 72 meningiomas. Cancer 66:152-155, 1990

35. Kaba SE, DeMonte F, Bruner JM, Kyritsis AP, Jaeckle KA, Levin V, et al: The treatment of recurrent unresectable and malignant meningiomas with interferon alpha-2B. Neurosurgery 40:271-275, 1997

36. Kaley TJ, Wen PY, Schiff D, Karimi S, DeAngelis LM, Nolan CP, et al: Phase II trial of sunitinib (SU011248) for recurrent meningioma. Neuro Oncol 12 (Suppl 4):iv75-iv76, 2010 (Abstract)

37. Kohler BA, Ward E, McCarthy BJ, Schymura MJ, Ries LA, Eheman C, et al: Annual report to the nation on the status of cancer, 1975-2007, featuring tumors of the brain and other nervous system. J Natl Cancer Inst 103:714-736, 2011

38. Koper JW, Zwarthoff EC, Hagemeijer A, Braakman R, Avezaat CJ, Bergström M, et al: Inhibition of the growth of cultured human meningioma cells by recombinant interferonalpha. Eur J Cancer 27:416-419, 1991

39. Lamszus K, Lengler U, Schmidt NO, Stavrou D, Ergün S, Westphal M: Vascular endothelial growth factor, hepatocyte growth factor/scatter factor, basic fibroblast growth factor, and placenta growth factor in human meningiomas and their relation to angiogenesis and malignancy. Neurosurgery 46:938948,2000

40. Lee JY, Kim H, Ryu CH, Kim JY, Choi BH, Lim Y, et al: Merlin, a tumor suppressor, interacts with transactivationresponsive RNA-binding protein and inhibits its oncogenic activity. J Biol Chem 279:30265-30273, 2004

41. Liu Y, Pang JC, Dong S, Mao B, Poon WS, Ng HK: Aberrant $\mathrm{CpG}$ island hypermethylation profile is associated with atypical and anaplastic meningiomas. Hum Pathol 36:416-425, 2005
42. Lou E, Sumrall AL, Turner S, Peters KB, Desjardins A, Vredenburgh JJ, et al: Bevacizumab therapy for adults with recurrent/progressive meningioma: a retrospective series. J Neurooncol 109:63-70, 2012

43. Loven D, Hardoff R, Sever ZB, Steinmetz AP, Gornish M, Rappaport ZH, et al: Non-resectable slow-growing meningiomas treated by hydroxyurea. J Neurooncol 67:221-226, 2004

44. Mason WP, Gentili F, Macdonald DR, Hariharan S, Cruz CR, Abrey LE: Stabilization of disease progression by hydroxyurea in patients with recurrent or unresectable meningioma. J Neurosurg 97:341-346, 2002

45. Mawrin C, Perry A: Pathological classification and molecular genetics of meningiomas. J Neurooncol 99:379-391, 2010

46. McCutcheon IE, Flyvbjerg A, Hill H, Li J, Bennett WF, Scarlett JA, et al: Antitumor activity of the growth hormone receptor antagonist pegvisomant against human meningiomas in nude mice. J Neurosurg 94:487-492, 2001

47. Mesa RA: Tipifarnib: farnesyl transferase inhibition at a crossroads. Expert Rev Anticancer Ther 6:313-319, 2006

48. Nassehi D: Intracranial meningiomas, the VEGF-A pathway, and peritumoral brain oedema. Dan Med J 60:B4626, 2013

49. Nayak L, Iwamoto FM, Rudnick JD, Norden AD, Lee EQ, Drappatz J, et al: Atypical and anaplastic meningiomas treated with bevacizumab. J Neurooncol 109:187-193, 2012

50. Newton HB, Scott SR, Volpi C: Hydroxyurea chemotherapy for meningiomas: enlarged cohort with extended follow-up. Br J Neurosurg 18:495-499, 2004

51. Norden AD, Hammond S, Drappatz J, Phuphanich S, Reardon DA, Wong E, et al: Phase II study of monthly pasireotide LAR (SOM230C) for recurrent or progressive meningioma. J Clin Oncol 29 Suppl:2040, 2011 (Abstract)

52. Norden AD, Raizer JJ, Abrey LE, Lamborn KR, Lassman AB, Chang SM, et al: Phase II trials of erlotinib or gefitinib in patients with recurrent meningioma. J Neurooncol 96:211-217, 2010

53. Nordqvist AC, Mathiesen T: Expression of IGF-II, IGFBP-2, -5 , and -6 in meningiomas with different brain invasiveness. $\mathbf{J}$ Neurooncol 57:19-26, 2002

54. Nordqvist AC, Peyrard M, Pettersson H, Mathiesen T, Collins VP, Dumanski JP, et al: A high ratio of insulin-like growth factor II/insulin-like growth factor binding protein 2 messenger RNA as a marker for anaplasia in meningiomas. Cancer Res 57:2611-2614, 1997

55. Nunes FP, Merker VL, Jennings D, Caruso PA, di Tomaso E, Muzikansky A, et al: Bevacizumab treatment for meningiomas in NF2: a retrospective analysis of 15 patients. PLoS ONE 8:e59941, 2013

56. Pachow D, Andrae N, Kliese N, Angenstein F, Stork O, WilischNeumann A, et al: mTORC1 inhibitors suppress meningioma growth in mouse models. Clin Cancer Res 19:1180-1189, 2013

57. Park YS, Lee JH, Harwalkar JA, Bondar J, Safayhi H, Golubic M: Acetyl-11-keto-beta-boswellic acid (AKBA) is cytotoxic for meningioma cells and inhibits phosphorylation of the extracellular-signal regulated kinase 1 and 2. Adv Exp Med Biol 507:387-393, 2002

58. Perry A, Cai DX, Scheithauer BW, Swanson PE, Lohse CM, Newsham IF, et al: Merlin, DAL-1, and progesterone receptor expression in clinicopathologic subsets of meningioma: a correlative immunohistochemical study of 175 cases. J Neuropathol Exp Neurol 59:872-879, 2000

59. Pfister C, Pfrommer H, Tatagiba MS, Roser F: Vascular endothelial growth factor signals through platelet-derived growth factor receptor $\beta$ in meningiomas in vitro. Br J Cancer 107: 1702-1713, 2012

60. Preusser M, Spiegl-Kreinecker S, Lötsch D, Wöhrer A, Schmook M, Dieckmann K, et al: Trabectedin has promising antineoplastic activity in high-grade meningioma. Cancer 118:5038-5049, 2012

61. Provias J, Claffey K, delAguila L, Lau N, Feldkamp M, Guha 
A: Meningiomas: role of vascular endothelial growth factor/ vascular permeability factor in angiogenesis and peritumoral edema. Neurosurgery 40:1016-1026, 1997

62. Puduvalli VK, Li JT, Chen L, McCutcheon IE: Induction of apoptosis in primary meningioma cultures by fenretinide. Cancer Res 65:1547-1553, 2005

63. Ragel BT, Couldwell WT, Wurster RD, Jensen RL: Chronic suppressive therapy with calcium channel antagonists for refractory meningiomas. Neurosurg Focus 23(4):E10, 2007

64. Ragel BT, Gillespie DL, Kushnir V, Polevaya N, Kelly D, Jensen RL: Calcium channel antagonists augment hydroxyurea- and ru486-induced inhibition of meningioma growth in vivo and in vitro. Neurosurgery 59:1109-1121, 2006

65. Ragel BT, Jensen RL: Aberrant signaling pathways in meningiomas. J Neurooncol 99:315-324, 2010

66. Reardon DA, Dresemann G, Taillibert S, Campone M, van den Bent M, Clement P, et al: Multicentre phase II studies evaluating imatinib plus hydroxyurea in patients with progressive glioblastoma. Br J Cancer 101:1995-2004, 2009

67. Rosenthal MA, Ashley DL, Cher L: Treatment of high risk or recurrent meningiomas with hydroxyurea. J Clin Neurosci 9:156-158, 2002

68. Salhia B, Rutka JT, Lingwood C, Nutikka A, Van Furth WR: The treatment of malignant meningioma with verotoxin. Neoplasia 4:304-311, 2002

69. Schrell UM, Rittig MG, Anders M, Kiesewetter F, Marschalek $\mathrm{R}$, Koch UH, et al: Hydroxyurea for treatment of unresectable and recurrent meningiomas. I. Inhibition of primary human meningioma cells in culture and in meningioma transplants by induction of the apoptotic pathway. J Neurosurg 86:845852,1997

70. Schrell UM, Rittig MG, Anders M, Koch UH, Marschalek R, Kiesewetter F, et al: Hydroxyurea for treatment of unresectable and recurrent meningiomas. II. Decrease in the size of meningiomas in patients treated with hydroxyurea. J Neurosurg 86:840-844, 1997

71. Sherman WJ, Raizer JJ: Chemotherapy: what is its role in meningioma? Expert Rev Neurother 12:1189-1195, 2012

72. Stamenkovic I, Yu Q: Merlin, a "magic" linker between extracellular cues and intracellular signaling pathways that regulate cell motility, proliferation, and survival. Curr Protein Pept Sci 11:471-484, 2010

73. Tichomirowa MA, Theodoropoulou M, Daly AF, Yassouridis A, Hansen S, Lu J, et al: Toll-like receptor-4 is expressed in meningiomas and mediates the antiproliferative action of paclitaxel. Int J Cancer 123:1956-1963, 2008

74. Todo T, Fahlbusch R: Accumulation of inositol phosphates in low-passage human meningioma cells following treatment with epidermal growth factor. J Neurosurg 80:890-896, 1994

75. Topalian SL, Drake CG, Pardoll DM: Targeting the PD-1/B7H1(PD-L1) pathway to activate anti-tumor immunity. Curr Opin Immunol 24:207-212, 2012

76. Tummalapalli P, Spomar D, Gondi CS, Olivero WC, Gujrati M, Dinh DH, et al: RNAi-mediated abrogation of cathepsin B and MMP-9 gene expression in a malignant meningioma cell line leads to decreased tumor growth, invasion and angiogenesis. Int J Oncol 31:1039-1050, 2007

77. Watson MA, Gutmann DH, Peterson K, Chicoine MR, Kleinschmidt-DeMasters BK, Brown HG, et al: Molecular characterization of human meningiomas by gene expression profiling using high-density oligonucleotide microarrays. Am J Pathol 161:665-672, 2002

78. Wellenreuther R, Kraus JA, Lenartz D, Menon AG, Schramm J, Louis DN, et al: Analysis of the neurofibromatosis 2 gene reveals molecular variants of meningioma. Am J Pathol 146:827-832, 1995

79. Wen PY, Quant E, Drappatz J, Beroukhim R, Norden AD: Medical therapies for meningiomas. J Neurooncol 99:365378, 2010

80. Wen PY, Yung WK, Lamborn KR, Norden AD, Cloughesy TF, Abrey LE, et al: Phase II study of imatinib mesylate for recurrent meningiomas (North American Brain Tumor Consortium study 01-08). Neuro Oncol 11:853-860, 2009

81. Yang SY, Xu GM: Expression of PDGF and its receptor as well as their relationship to proliferating activity and apoptosis of meningiomas in human meningiomas. J Clin Neurosci 8 (Suppl 1):49-53, 2001

82. Yazaki T, Takamiya Y, Costello PC, Mineta T, Menon AG, Rabkin SD, et al: Inhibition of angiogenesis and growth of human non-malignant and malignant meningiomas by TNP470. J Neurooncol 23:23-29, 1995

83. Zhou H, Luo Y, Huang S: Updates of mTOR inhibitors. Anticancer Agents Med Chem 10:571-581, 2010

Manuscript submitted August 14, 2013.

Accepted October 4, 2013.

Please include this information when citing this paper: DOI: 10.3171/2013.10.FOCUS13341.

Address correspondence to: Gabriel Zada, M.D., Department of Neurosurgery, University of Southern California, 1200 N. State St., Ste.3300, Los Angeles, CA 90033.email: gzada@usc.edu. 